\title{
Sri Lankan fetal/ birthweight charts: validation of global reference for fetal weight and birthweight percentiles
}

\author{
V Shanmugaraja, S G Kumarasiri, S L Wahalawatte, R V Wanigasekara, P Begam, P K C L Jayasinghe, \\ T Padeniya, T Dias
}

(Index words: Sri Lankan, birthweight, validation)

\begin{abstract}
Introduction Small for gestational age (SGA) is defined as birthweight below the tenth centile at a particular gestational week. Birthweight centiles for different populations are varied. Generic reference for fetal weight and birthweight that could be adapted to local populations was recently described. The purpose of this study was to validate the reference for birthweights adapted to the local population.

Methods This was a prospective validation study done between January 2012 and July 2012 in well dated pregnancies at General Hospital, Ampara. Observed frequencies of birthweights of 5th, 10th, 50th, 90th and 95th percentiles for Hadlock formula, World Health Organization (WHO) global survey data for Sri Lanka and India were calculated. The expected frequencies for each birthweight centile of our study were compared with observed frequencies.
\end{abstract}

Results A total of 411 patients were recruited and 207 delivered at 40 weeks $\left(40^{+0}-40^{+6}\right)$. The mean birth-weight (SD) at 40 weeks of gestation was $3140 \mathrm{~g}(432 \mathrm{~g})$. Hadlock formula and WHO reference data for India overestimate and underestimate most of the birthweights respectively. WHO generic reference adapted to Sri Lanka fitted well with our data. The mean birthweight of our population is similar, and the adapted reference range would identify most of the small fetuses correctly. It would also identify almost all the babies with weight above the 90th centile.

Conclusions The findings of the study show that the observed distribution of birthweight fitted well with the reference range derived from the $\mathrm{WHO}$ global reference range adapted to Sri Lankan population. WHO reference charts can be used effectively in Sri Lankan population.

Ceylon Medical Journal 2013; 58: 62-65

\section{Introduction}

Small for gestational age (SGA) carries a higher risk of various adverse outcomes in the perinatal period [1-6].
SGA is generally defined as birthweight or fetal weight below the tenth percentile at a particular gestational week. There is no uniformity in this definition as the 5th or 3rd percentiles are also used sometimes to assess the severity of SGA [7]. Birthweight is often influenced by maternal ethnicity, BMI, parity and some undetermined causes [8]. Accurate determination of fetal/ birthweight percentiles for a given gestation is important as it reduces the complications of a misdiagnosed SGA fetus. It also helps in making early decisions with regard to delivery and avoiding unnecessary interventions and saves resources [8].

Hadlock and colleagues formulated an optimum growth equation based on ultrasound measurements between 10 and 41 weeks of gestation of 392 pregnant Caucasian women [9]. They also showed that the statistical variation of fetal weight in a given gestational week was a constant fraction of the mean. Hadlock's growth equation is given below [9].

Fetal weight $(\mathrm{g})=\exp \left(0.578+0.332 \times \mathrm{GA}-0.00354 \times \mathrm{GA}^{2}\right)$

However, this formula was not popular as it often either under or over estimated the fetal/ birthweight in other populations. In order to overcome this limitation individualised reference charts using Hadlock formula were proposed [10]. This standardised fetal weight derived from Hadlock formula for various factors such as parity, ethnicity, sex of infant, maternal height and weight by transforming it into a so called proportionality function. Recently, a weight reference easily adjustable according to the mean birth weight at 40 weeks of gestation for any local population was made using above two methods [11]. Once the mean birthweight and standard deviation (SD) of birthweight at 40 weeks is identified, the mean and SD of fetal weight and birthweight for all gestational weeks are fixed. They validated their method for 24 countries in Africa, Latin America, and Asia that participated in the 2004-08 WHO Global Survey on Maternal and Perinatal Health (237 025 births). The aim of this study was to validate the fetal/birthweight reference derived from WHO data for birthweights adapted to Sri Lankan population. 


\section{Methods}

This was a prospective validation study done between January 2012 and July 2012 in General Hospital, Ampara, Sri Lanka. Ultrasound gestational age assessment was routinely offered to all pregnant women. All pregnancies were dated by crown-rump length (CRL) at 11-14 weeks and by head circumference (HC) thereafter $[12,13]$. Fetal CRL and HC were measured by trained operators using ultrasound machine GE logic 3. Robinson and Chitty formulae were used for CRL and $\mathrm{HC}$ respectively to calculate gestational age [14]. Only uncomplicated singleton live births were included in the study. Data on birthweight and gestation at delivery were documented in a purposely designed data entry sheet at the delivery.

Expected frequencies for birthweight centile 5th, 5th to 10 th, 10th to 90 th and $>95$ th for deliveries between $40^{+0}$ and $40^{+6}$ of our study were calculated. Mean birthweight and the coefficient of variation at 40 weeks were considered to calculate the observed birthweights for Hadlock formula, the WHO global survey data for Sri Lanka and for India. Subsequently, observed frequencies of birthweight centiles $<5$ th, 5 th to 10 th, 10 th to 90 th and $>95$ th for Hadlock formula, WHO data for Sri Lanka and India were compared with expected frequencies of our study.

Chi square value for each observed centile frequency and the overall Chi square value of observed frequency for Hadlock formula, WHO data for Sri Lanka and WHO data for India were calculated. If the overall difference between observed and expected frequencies is not significant $(p>0.05)$ respective fetal/birthweight charts can be used reliably in the Sri Lankan population. Approval for the study was obtained from the ethics review board of General Hospital, Ampara.

\section{Results}

A total of 411 patients were recruited to our study and 207 delivered at 40 weeks $\left(40^{+0}-40^{+6}\right)$. The mean maternal age was 27.01 years, majority were nulliparous. The median gestational age at birth was 40 weeks. The mean birthweight at 40 weeks of gestation was $3140 \mathrm{~g}$ (Table 1). Expected frequencies of birthweight centiles $<5$ th, 5th to 10th, 10th to 90th and $>95$ th from our data and observed frequencies for Hadlock formula, WHO data for Sri Lanka and WHO data for India are given in Table 2. It is apparent that the Hadlock's observed frequencies significantly overestimate birthweights whereas the WHO Indian data significantly underestimates birthweights in Sri Lankan population (Figures 1 and 3).

Results of observed frequencies of birthweights for WHO global reference range adapted for Sri Lanka are very similar to expected frequencies of our data for all centiles (Figure 3). We can effectively identify most of SGA babies including severe SGA (<5th centile) using the charts adapted from WHO global survey for Sri Lanka. Furthermore, large for gestational age (LGA) babies can also be identified.

Table 1. Demographic details of women participating in the study (BMI: body mass index, CRL: crown rump length, HC: head circumference, IQR: interquartile range, GA; gestational age, SD: standard deviation)

\begin{tabular}{lc}
\hline Mean maternal age (SD) & $27.01(5.40)$ \\
BMI (Median and IQR) & $20(2.2)$ \\
Number of nulliparous women (\%) & $204(49.75)$ \\
CRL dating between 11 and 14 weeks (\%) & $290(70.73)$ \\
HC dating after 14 weeks (\%) & $129(29.27)$ \\
Median GA at birth in days (IQR) & $280(6)$ \\
Women delivered between $40^{+0}$ and $40^{+6}$ & $3140(432)$ \\
Mean birthweight at 40 weeks in grams (SD)
\end{tabular}
Table 2. Expected frequencies of birthweight centiles $<5$ th, 5 th to 10 th, 10 th to 90 th and $>95$ th from our data and observed frequencies for Hadlock formula (Mean 3750, SD 476), WHO data for Sri Lanka (Mean 3079, SD 399) and WHO data for India (Mean 2790, SD 396)

\begin{tabular}{|c|c|c|c|c|c|c|c|}
\hline $\begin{array}{l}\text { Centile } \\
\text { range }\end{array}$ & $\begin{array}{l}\text { Expected } \\
\text { frequency }\end{array}$ & $\begin{array}{l}\text { Observed } \\
\text { frequency } \\
\text { from Hadlock } \\
\text { formula }\end{array}$ & $\begin{array}{l}\text { Chi square } \\
\text { value for } \\
\text { Hadlock } \\
\text { formula }\end{array}$ & $\begin{array}{c}\text { Observed } \\
\text { frequency } \\
\text { from WHO data } \\
\text { for Sri Lanka }\end{array}$ & $\begin{array}{c}\text { Chi square } \\
\text { value for WHO } \\
\text { data for } \\
\text { Sri Lanka }\end{array}$ & $\begin{array}{c}\text { Observed } \\
\text { frequency } \\
\text { from WHO } \\
\text { data for India }\end{array}$ & $\begin{array}{l}\text { Chi square } \\
\text { value for } \\
\text { WHO data } \\
\text { for India }\end{array}$ \\
\hline$<5$ th & 10.30 & 64 & 279.97 & 8 & 0.51 & 3 & 5.17 \\
\hline 5th to 10 th & 10.30 & 16 & 3.15 & 8 & 0.51 & 3 & 5.17 \\
\hline 10th to 90 th & 164.8 & 126 & 9.13 & 161 & 0.88 & 104 & 22.43 \\
\hline 90th to 95 th & 10.30 & 0 & 10.30 & 14 & 1.33 & 27 & 27.08 \\
\hline$>95$ th & 10.30 & 0 & 10.30 & 15 & 2.14 & 69 & 334.53 \\
\hline \multicolumn{2}{|l|}{ Chi square } & & 312.85 & & 5.37 & & 394.38 \\
\hline \multicolumn{2}{|c|}{ p value (degree of freedom 4) } & & $<0.001$ & & 0.25 & & $<0.001$ \\
\hline
\end{tabular}




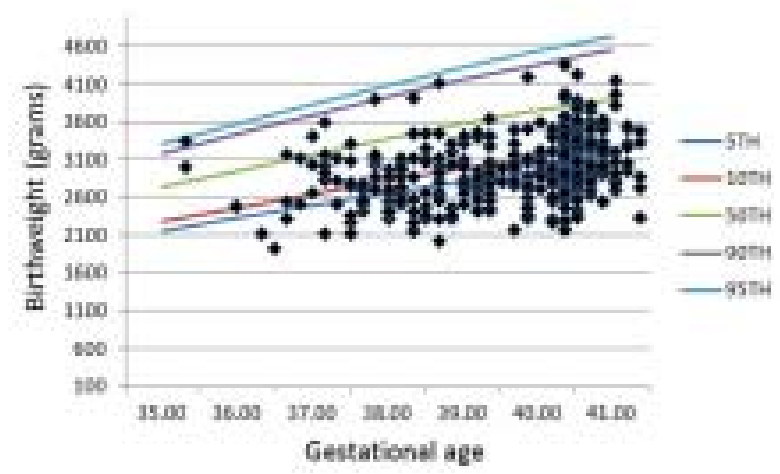

Figure 1. Distribution of birthweights based on Hadlock formula.

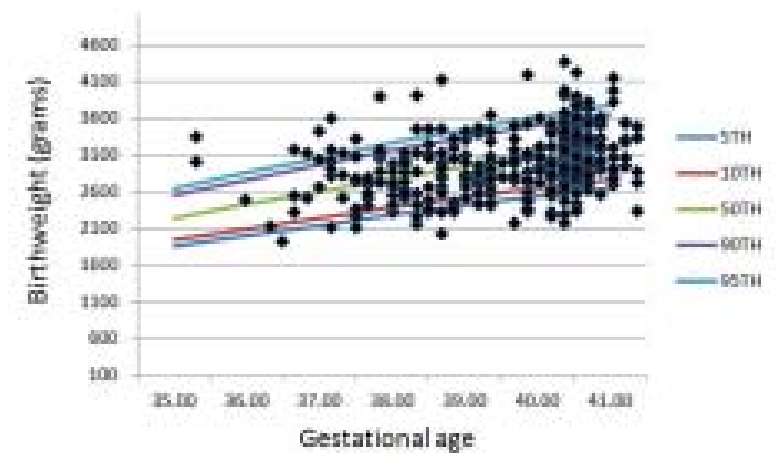

Figure 2. Distribution of birthweights using WHO generic reference range adapted for India.

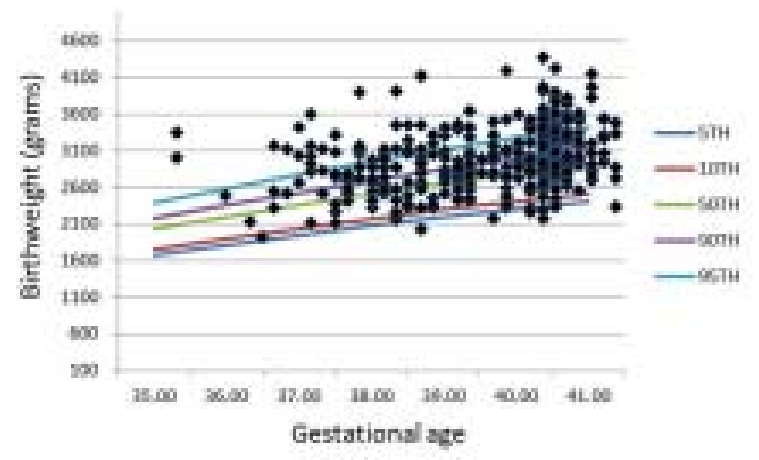

Figure 3. Distribution of birthweights using WHO generic reference range adapted for Sri Lanka.

\section{Discussion}

Small-for-gestational age fetuses are at increased risk of pregnancy complications mainly perinatal death and handicap [15]. These risks can be substantially reduced if cases of SGA identified antenatally, compared to those detected after birth [16]. The findings of our study show that the observed distribution of birthweights fitted with the reference range derived from the global reference range adapted to Sri Lankan population based on the WHO survey. The mean birthweight of our population is similar, and the adapted reference range would identify most small fetuses including severe SGA babies correctly. It would also identify almost all the LGA babies that is birthweight $>90$ th centile. Hence, WHO reference charts can be used effectively in Sri Lankan population.

In the case of large ethnic differences; adjustment for ethnicity improves the classification of small for gestational age substantially [11]. Moreover, addition of more parameters for individualisation provides little further improvement against the ethnicity-adjusted reference. However, findings of our study did not support this, even within the same ethnic group there is a huge difference in fetal/birthweight reference. If we adapt Indian reference, $40 \%$ of our babies would be LGA and very few would be SGA. Hadlock reference ranges did not fit our data and it significantly overestimates birthweights. According to Hadlock formula more than $50 \%$ of term babies would be SGA and none of term babies were LGA. This finding was similar to the study by Mikolajczyk et al which reported that the Hadlock charts would result in $60 \%$ of fetuses being labeled as SGA.

It has been the practice for nearly half a century to use birthweight references based on neonates born at different gestational weeks [15]. Later, it was realised that there were marked discrepancy in 10th centile for the weight of born preterm neonates and unborn fetuses and neonates at a particular gestational week indicating infants born before term are more likely to be growth restricted [16-18]. The discrepancy could be large in early gestational weeks, which could substantially under diagnose small for gestational age in preterm births or fetuses. Therefore one could argue that ultrasound-based estimated references of fetal weight are a better choice. However, ultrasound-based references were mostly adapted from data of Caucasian population and they might not be applicable to ethnic groups living in most developing countries [11]. In order to overcome this limitation, we considered mean birthweight and the co-efficient of the variance at 40 weeks as described by others $[9,10]$.

The main strength of our study is that we managed to offer ultrasound gestational age assessment during the first half of the pregnancy to all the participants. Moreover, we have included fairly large numbers of participants at term.

\section{Conclusions}

We have shown that global reference curves adapted on the basis of WHO data for Sri Lanka fit our population and these charts can now be readily used to assess the severity of growth problems in Sri Lankan babies. We 
also showed that charts based the Hadlock formula do not fit the Sri Lankan population. Furthermore, fetal/ birthweight charts cannot be generalised even among the same ethnic groups. Users should adopt only those curves where the population for which it is modified matches their own population in terms of maternal demographics.

\section{References}

1. Ott WJ. Small for gestational age fetus and neonatal outcome: reevaluation of the relationship. American Journal Perinatology 1995; 12: 396-400.

2. Doctor BA, O’Riordan MA, Kirchner HL, Shah D, Hack M. Perinatal correlates and neonatal outcomes of small for gestational age infants born at term gestation. American Journal of Obstetrics and Gynecology 2001; 185: 652-9.

3. Smedler AC, Faxelius G, Bremme K, Lagerstrom M. Psychological development in children born with very low birth weight after severe intrauterine growth retardation: a 10-year follow-up study. Acta Paediatrician 1992; 81: 197-203.

4. Sung IK, Vohr B, Oh W. Growth and neurodevelopmental outcome of very low birth weight infants with intrauterine growth retardation: comparison with control subjects matched by birthweight and gestational age. The Journal of Paediatrics 1993; 123: 618-24.

5. Verkauskiene R, Figueras F, Deghmoun S, Chevenne D, Gardosi J, Levy-Marchal M. Birth weight and long-term metabolic outcomes: does the definition of smallness matter? Hormone Research Paediatrics 2008; 70: 309-15.

6. von Ehrenstein OS, Mikolajczyk RT, Zhang J. Timing and trajectories of fetal growth related to cognitive development in childhood. American Journal of Epidemiology 2009; 170: $1388-95$.

7. Zhang J, Merialdi M, Platt LD, Kramer MS. Defining normal and abnormal fetal growth: promises and challenges. American Journal of Obstetrics and Gynecology 2010; 202: 522-8.
8. Chauhan SP, Gupta LM, Hendrix NW, Berghella V. Intrauterine growth restriction: comparison of American College of Obstetricians and Gynecologists practice bulletin with other national guidelines. American Journal of Obstetrics and Gynecology 2009; 200: 409 e1-6.

9. Hadlock F, Harrist R, Martinez-Poyer J. In Utero Analysis of fetal growth: A sonographic weight standard'. Radiology 1991; 181: 129-33.

10. Gardosi J, Mongelli M, Wilcox M, Chang A. An adjustable fetal weight standard. Ultrasound Obstetrics and Gynecology 1995; 6: 168-74.

11. Mikolajczyk RT, Zhang J, Betran AP, et al. Global reference for fetal-weight and birthweight percentiles. Lancet 2011; 377: 1855-61.

12. Taipale P, Hiilsemaa V. Predicting Delivery Date by Ultrasound and last menstrual period in early gestation. Obstetrics and Gynecology 2001; 97: 189-94.

13. Antenatal care. Routine care for the healthy pregnant woman. Clinical Guideline 6. National Institute of Clinical Excellence. 2003. www.nice.org.uk

14. Loughna P, Chitty L, Evans T, Chudleigh T. Fetal size and dating: charts recommended for clinical obstetric practice. Ultrasound 2009; 17: 161-7.

15. Alexander GR, Himes JH, Kaufman RB, Mor J, Kogan M. A United States national reference for fetal growth. Obstetrics and Gynecology 1996; 87: 163-8.

16. Zhang X, Platt RW, Cnattingius S, Joseph KS, Kramer MS. The use of customised versus population-based birthweight standards in predicting perinatal mortality. British Journal of Obstetrics and Gynecology 2007; 114: 474-7.

17. Williams RL, Creasy RK, Cunningham GC, Hawes WE, Norris FD, Tashiro M. Fetal growth and perinatal viability in California. Obstetrics and Gynecology 1982; 59: 624-32.

18. Lindqvist PG Molin J. Does antenatal identification of smallfor-gestational age fetuses significantly improve their outcome? Ultrasound in Obstetrics and Gynecology 2005; 25: $258-64$

\section{Erratum}

The Notice of Retraction of the abstract entitled, "Factor V Hong Kong and Cambridge mutations are absent in patients with deep vein thrombosis", published in Ceylon Medical Journal 2011; 56: 187 was an error. The authors have not retracted the abstract. We regret the error.

\section{Joint Editors, CMJ}

